\title{
The social structural foundations of adaptation and transformation in social-ecological systems
}

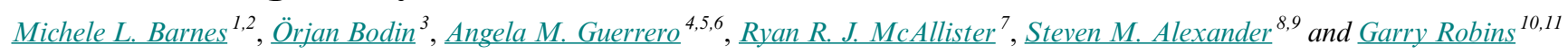

\begin{abstract}
Social networks are frequently cited as vital for facilitating successful adaptation and transformation in linked socialecological systems to overcome pressing resource management challenges. Yet confusion remains over the precise nature of adaptation vs. transformation and the specific social network structures that facilitate these processes. Here, we adopt a network perspective to theorize a continuum of structural capacities in social-ecological systems that set the stage for effective adaptation and transformation. We begin by drawing on the resilience literature and the multilayered action situation to link processes of change in social-ecological systems to decision making across multiple layers of rules underpinning societal organization. We then present a framework that hypothesizes seven specific social-ecological network configurations that lay the structural foundation necessary for facilitating adaptation and transformation, given the type and magnitude of human action required. A key contribution of the framework is explicit consideration of how social networks relate to ecological structures and the particular environmental problem at hand. Of the seven configurations identified, three are linked to capacities conducive to adaptation and three to transformation, and one is hypothesized to be important for facilitating both processes. We discuss how our theoretical framework can be applied in practice by highlighting existing empirical examples from related environmental governance contexts. Further extension of our hypotheses, particularly as more data become available, can ultimately help guide the design of institutional arrangements to be more effective at dealing with change.
\end{abstract}

Key Words: adaptation; adaptive capacity; social-ecological system; social network; social-ecological network; transformation

\section{INTRODUCTION}

The capacity to adapt or transform institutional structures and processes is critical to maintaining ecosystem services and avoiding (or potentially escaping from) social-ecological traps (Adger et al. 2005, Folke et al. 2005, Nelson et al. 2007, Kittinger et al. 2013, Chaffin et al. 2016). Adaptability and transformability are fundamental to the theory of resilience (Folke et al. 2010). The concept of resilience, emphasizing the interdependent nature of people and ecosystems, describes the ability of linked socialecological systems (SESs) to tolerate unknown or unforeseen shocks by absorbing, accommodating, or embracing change (adaptation), or to fundamentally reorganize as a response to challenges that are impossible to address within a current SES state or regime (transformation) (Walker et al. 2004, Folke et al. 2010). Resilience thus offers a forward-looking vision of sustainability where people anticipate change and are more capable of influencing future trajectories (Berkes and Seixas 2005), rather than reacting to crises when it may be too late (Cinner 2011).

Both adaptation and transformation require adaptive capacity among social actors and institutions in order to absorb and shape change (Nelson et al. 2007, Engle 2011). It has been widely acknowledged that social networks, defined as social relationships between individuals and groups, are crucial for building this capacity (e.g., Adger 2003, Berkes et al. 2003, Armitage et al. 2009, Brondizio et al. 2009; Cinner et al., unpublished manuscript). Social networks provide a means for sharing knowledge, resources, and support and facilitate opportunities to build trust and social capital (Bodin and Crona 2009) - all of which are critical for effective decision making in response to disturbance and change (Folke et al. 2010, Alexander et al. 2016, Chaffin et al. 2016). For example, knowledge sharing facilitates learning, a key element of adaptive capacity (Nelson et al. 2007). Likewise, social capital can reduce the transaction costs associated with coordinating responses and collaborating across institutional scales to develop more effective strategies to deal with change (Adger 2003, Berardo 2014, Henry and Vollan 2014).

Despite widespread recognition of the importance of social networks for adaptation and transformation, how, which, and in what contexts specific network structures lay the foundation for these processes to occur remain unclear. For example, existing research suggests ties linking actors at different scales or hierarchical levels (i.e., linking ties) are critical for transformation (Olsson et al. 2004, Nelson et al. 2007). Clearly the effectiveness of such ties for supporting transformation depends in part on the norms, wisdom, and intent of the actors who hold them (ElderVass 2010). Yet, from a structural perspective, does it matter if such ties are simply present in a somewhat random way? Or is it important for certain actors (i.e., nodes) in a network to possess linking ties, and do different subgroups of actors require more or fewer such ties? Similarly, the manner in which social networks explicitly relate to ecological dynamics and the specific environmental problem driving the need for adaptation or transformation has received little attention in the literature. Yet understanding these links and feedbacks is critical for understanding how the system will respond to both social and

\footnotetext{
${ }^{1}$ ARC Centre of Excellence for Coral Reef Studies, James Cook University, ${ }^{2}$ Department of Botany, University of Hawaii at Manoa, ${ }^{3}$ Stockholm Resilience Centre, Stockholm University, Sweden, ${ }^{4}$ School of Biological Sciences, The University of Queensland, ${ }^{5}$ ARC Centre of Excellence for Environmental Decisions, The University of Queensland, ${ }^{6}$ Luc Hoffmann Institute, WWF International, ${ }^{7}$ CSIRO, ${ }^{8}$ Stockholm Resilience Centre, Stockholm University, ${ }^{9}$ National Socio-Environmental Synthesis Center, University of Maryland, ${ }^{10}$ Melbourne School of Psychological Sciences, University of Melbourne, ${ }^{11}$ Centre for Transformative Innovation, Swinburne University of Technology
} 
ecological change (Bodin 2017, Hughes et al. 2017) and whether certain changes will strengthen or dampen feedbacks that may tip the system into an undesirable state that could be difficult or impossible to reverse (i.e., a social-ecological trap) (Kittinger et al. 2013).

Here, we adopt a structural approach to propose an initial set of network capacities that set the stage for effective adaptation and transformation in linked SESs. Although adaptation and transformation can originate in ecological components of linked SESs, here we focus on the social dimension, i.e., the ability of people to adapt to and shape change. Yet because of the linked dynamics of SESs, this focus cannot exclude constraints presented by the natural environment. The network capacities we present thus explicitly account for key structural characteristics of ecosystems and their relationships with people. Acknowledging that SESs can face a range of environmental and social problems that may require different network capacities to facilitate effective responses, we specifically focus on the "common-pool problem," where a multitude of actors more or less compete for the same resource and/or set of interdependent resources (Hardin 1968, Ostrom 1990). We leave for future work analogous theorizations for other types of ecological challenges.

We begin by drawing on the resilience literature and the three levels of rules associated with Kiser and Ostrom's (1982) multilayered action situation to clarify some of the conceptual and practical differences between adaptation and transformation. We then develop hypotheses about how specific patterns of relationships within and between people and nature lay the foundation necessary to facilitate adaptation or transformation. These hypotheses were refined through an in-depth review of the social processes highlighted as important for adaptation and transformation in the resilience and sustainability science literature, coupled with multiple workshops held between 20152017 where these processes were deliberated and discussed in relation to network theory by an interdisciplinary team of scholars and practitioners. Our arguments draw on a multilevel "social-ecological network" approach (Bodin and Tengö 2012, Wang et al. 2016), contributing a novel theorization of how social structures relate to ecological structures and the specific environmental problem at hand. Rather than provide an exhaustive review of all processes that might be relevant for adaptation or transformation, we focused on a set of processes where the network perspective was particularly relevant. We outline how our framework builds on existing research in environmental governance contexts and discuss how it can be applied empirically using a combination of methods. We conclude by discussing the potential for future extension of our hypotheses, with the ultimate goal of guiding the design of institutional arrangements to be more effective at dealing with change.

\section{ADAPTATION, TRANSFORMATION, AND THE MULTILAYERED ACTION SITUATION}

There have been, and still are, scholarly debates about adaptation and transformation with regard to their specific characteristics and definitions (e.g., Walker et al. 2004, Nelson et al. 2007, Wilson et al. 2013). Although these debates have brought increased clarity, ambiguities remain as to what exactly differentiates adaptation from transformation. Here, we contribute to ongoing conceptual developments of these concepts in the resilience literature (e.g., Folke et al. 2010, Moore et al. 2014) by synthesizing previous work on these processes and more closely linking them with the well-known institutional analysis and development (IAD) framework (see McGinnis and Ostrom 2014). Specifically, we link adaptation and transformation with the three distinct levels of rules associated with the multilayered action situation, thereby providing a means to more precisely distinguish adaptation from transformation in terms of the social or institutional responses of an affected community. Linking these concepts makes it easier to discuss the magnitude and nature of human responses to a disturbance, while also paving the way for a tighter integration between the scholarship and literatures of IAD and adaptationtransformation. However, we do not claim this settles the issue as to what exactly distinguishes a transformation from an adaptation. Although we argue our conceptualization contributes increased clarity and facilitates empirical inquiries drawing from a broader set of theories and methods, substantial work remains to integrate different streams of literatures and conceptualizations if a fully coherent and widely accepted transformation and adaptation framework is to be established.

Adaptation is defined by Berkes et al. (2003) as the capacity of a SES to learn, combine experiences and knowledge, and adjust responses to changing external drivers and internal processes while continuing to develop within the current stability domain or basin of attraction. Thus, adaptation implies the maintenance of certain SES processes despite changing internal demands (e.g., local increases in human population) or external forces (e.g., global economic crises) (Carpenter and Brock 2008, Folke et al. 2010). Adaptation thus captures adjustments taken in response to disturbances (social or ecological, externally or internally driven) that can be initiated and executed largely within the current structures and procedures of a SES. These adjustments are often described as incremental and made in response to small or moderate changes in current conditions (Nelson et al. 2007, Folke et al. 2010, Park et al. 2012, Dowd et al. 2014).

Transformation is defined by Walker et al. (2004) as the capacity to create a fundamentally new system when changes in ecological, economic, or social structures make the existing system untenable. For example, the gravity of climate change impacts may result in a SES no longer being able to support traditional livelihood systems such as farming, causing farmers to seek alternative livelihood strategies. When these alternative strategies play out at scale, they not only involve engagement in entirely new ways to use land, but most likely require institutional change to allow new supply chains, access to new markets, or even alteration of the conditions of land tenure, which frequently dictate allowable land uses. Transformation thus often involves more significant changes than adaptation because it requires system elements to be recombined in fundamentally novel ways (Moore et al. 2014). Unlike adaptation, the changes involved in a transformation can impact dominant social-ecological feedbacks, which can lead to further social and ecological changes (Moore et al. 2014). Many scholars argue that certain large external or internal changes require that affected communities transform (and not just adapt), otherwise they risk being trapped in an undesired state (Folke et al. 2010, Moore et al. 2014). Thus, transformation is at least partly defined as when the magnitude of change needed in order to avoid an undesired state following a disturbance exceeds what fits within the definition of adaptation (Wise et al. 2014). In a sense, 
transformation can thus be seen as a continual extension of adaptation (Fig. 1), and the exact location on this gradient where adaptation becomes transformation might be inherently difficult to define and predict (Nelson et al. 2007). It is possible that a dramatic external shock may result in a rapid phase change in the system, such that adaptation is simply unfeasible, and efforts at transformation are then more readily distinguished.

Fig. 1. A theoretical organizing framework that links processes of change in social-ecological systems to Kiser and Ostrom's (1982) multilayered action situation of the IAD framework, which conceptualizes decision making with rules of different types that fall within a hierarchy.

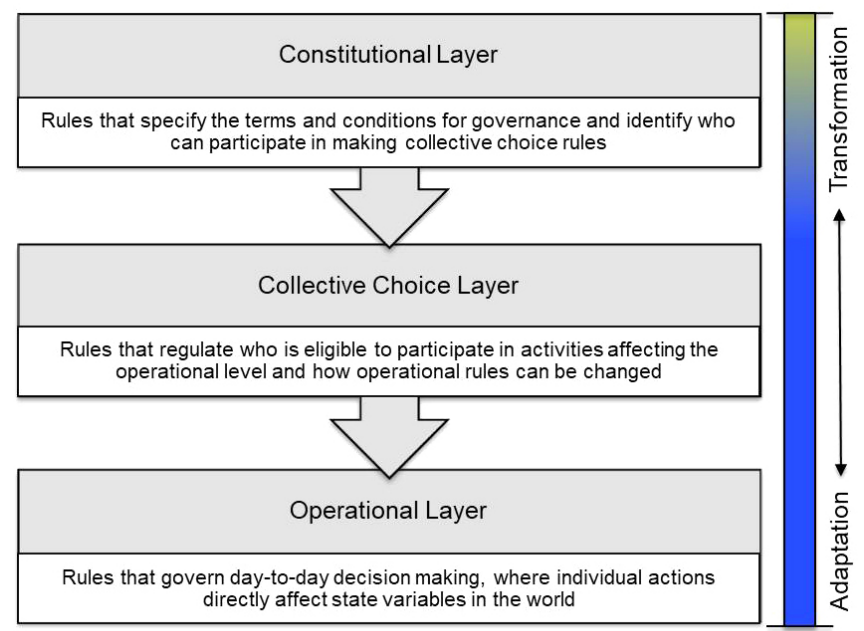

To varying degrees, both adaptation and transformation require changes in human behavior and the norms and rules that guide it. Adaptation requires people to adjust their behavior in response to disturbance and may also induce changes in how certain institutions, or rules, are structured (Adger et al. 2005). Similarly, navigating a transformation implies inducing changes in human behavior and coordinating institutions and rules at different organizational levels of society (Adger et al. 2005). We therefore argue that conceptual clarity can be improved by more closely linking transformation and adaption to the multilayered action situation model of the IAD framework (Kiser and Ostrom 1982, Ostrom 2009).

The multilevel action situation consists of three different layers: (1) constitutional rules, (2) collective choice rules, and (3) operational rules (Kiser and Ostrom 1982; Fig. 1). The three layers of rules form a hierarchy, with the rules on a higher layer deciding the degrees of freedom for those on the lower layer. "Constitutional rules" specify the terms and conditions for governance, stipulating who possesses the right to make decisions about access and resource utilization as well as who is eligible to share the benefit of its use. Constitutional-layer choices relate to who is or should be empowered to participate in the making of collective or operational layer decisions (i.e., decisions about decision rules). "Collective choice rules" regulate how decisions are made (e.g., in order to decide the level of harvesting or technological input). Collective decisions made by officials can be to determine, enforce, continue, or alter actions authorized within institutional arrangements. Furthermore, they are enforceable against nonconforming individuals (unlike operational rules), and the authority to impose sanctions is a key attribute. "Operational rules" regulate daily activities (e.g., intensity of harvesting or methods of cultivating). Individuals functioning at this layer either take direct action or adopt a strategy for future actions. This is the only layer where an action in the physical world flows directly from a decision.

In linking the multilayered action situation with adaptation and transformation, we suggest that adaptation (i.e., responding to manageable challenges within the same system) involves changes or adjustments in the operational layer that do not require reengineering the constitutional layer. In contrast, transformations imply changes in the constitutional layer, which in turn can affect all layers underneath (i.e., collective choice, operational) (Fig. 1). This aligns well with how Moore et al. (2014) describe transformation as changes to rules and practices (such as laws, procedures, and customs) and with recent empirical evidence from Chile regarding changes in regulatory structures associated with a transformation (Gelcich et al. 2010). We argue that transformation and adaptation essentially "meet" at the collective choice layer, suggesting that both transformation and adaptation, to a varying degree, imply changes in collective choice rules (adaptation would, as we argue here, always involve changes in collective choices, but not necessarily changes in collective choice rules). Following our conceptualization of adaptation and transformation being on different ends of a gradient, the transition point where they change into one another is in the collective choice layer, although again, its precise location will be contextual and inherently difficult to define and predict (Fig. 1).

Several key social processes that imply or require changes in the rules guiding human behavior have been identified as important for effectively navigating a transformation and providing the capacity to adapt to changing conditions in complex SESs. In the following section, we present a framework with specific hypotheses that capture the social structural foundations of these processes, which we refer to as "network capacities." Drawing on SES theory and the multilayered action situation, these capacities explicitly account for complex links and feedbacks between people and nature to capture human actions that can be taken at different layers of societal organization in response to (or in anticipation of) change.

\section{THE SOCIAL STRUCTURAL FOUNDATIONS OF ADAPTATION AND TRANSFORMATION}

Social-ecological systems are inherently complex, consisting of links and feedbacks within and between people and nature. These interactions are important because they can facilitate or constrain human action in different contexts. Because it emphasizes relationships and interdependencies rather than a set of state variables, a multilevel social-ecological network perspective (Fig. $2 a$ ) offers a fruitful approach for theorizing and empirically investigating these social-ecological interactions. To date, this approach has been applied to studies of land and water management in addition to studies of landscape conservation (Bergsten et al. 2014, Guerrero et al. 2015b, Kininmonth et al. 2015, Prager and Pfeifer 2015, Sayles and Baggio 2017). When coupled with relevant theory, full multilevel social-ecological 
networks can be disassembled into a set of precisely defined, key social-ecological network configurations (Fig. 2b), or "building blocks" that lay the foundation for larger network structures (Bodin and Tengö 2012). Here, the link with theory and processes is key; the configurations serve as the "glue" between theory providing a process-based causal understanding of behaviors and outcomes, and the empirics describing a coupled SES as composed of a multitude of entangled actors and ecological resources. Another way to express this is that a social-ecological network represents a "structural fingerprint" of the diversity of social and ecological processes constituting a SES (Bodin et al. 2016a), while simultaneously also capturing key conditions and constraints impacting further behaviors and outcomes thereof.

Fig. 2. A social-ecological system (SES) represented as a social-ecological network (A), and how key network configurations act as building blocks that support larger socialecological structures (B). The multilevel structure captures the dependencies that exist within the system, i.e., how social and ecological system elements relate to and depend on each other, and the constraints and opportunities social actors face in taking actions within the system structure.
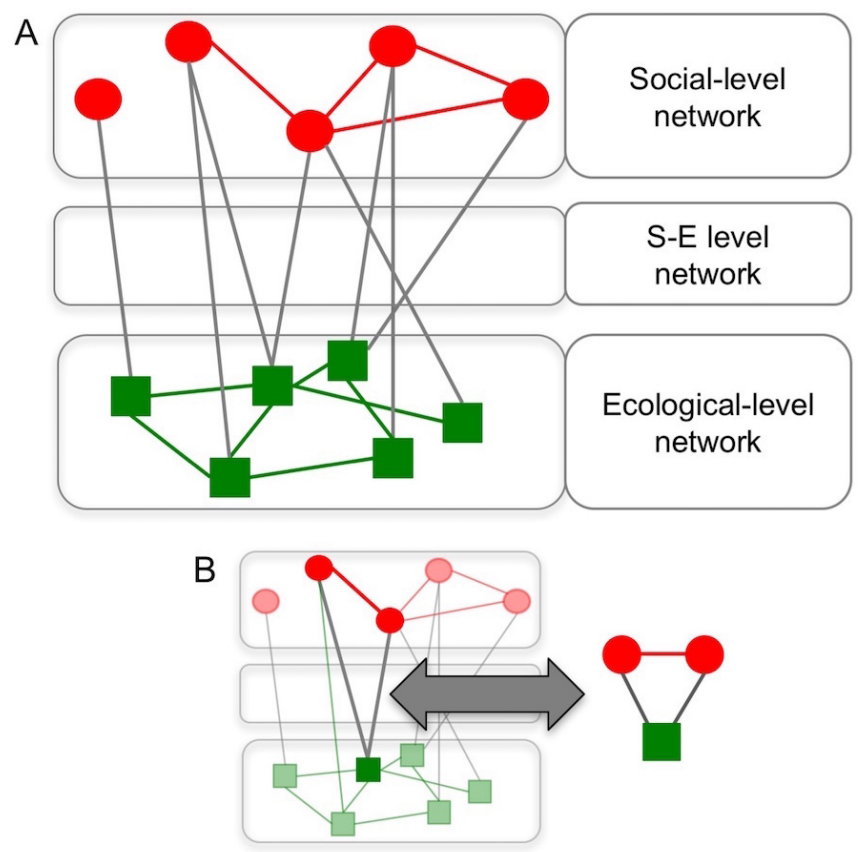

The idea that social networks could be described in terms of the prevalence of small network substructures (i.e., configurations) goes back to the foundations of social network analysis (Moreno and Jennings 1938, Holland and Leinhardt 1970) and has more recently been discussed in the context of biological networks as the analysis of "network motifs" (Milo et al. 2002) (in this paper, we use Moreno's initial term "configurations"). Social-ecological network configurations comprise a limited set of social and/or ecological nodes and the patterns of links that exist between them. These configurations represent the prevalence of key relationships within and between social actors and ecological resources that can be important for achieving desirable outcomes in the context of particular environmental problems. For example, recent research has suggested that the over (or under) representation of certain network configurations can help explain and more precisely define different governance challenges faced in complex SESs, such as institutional fit (Bodin and Tengö 2012, Guerrero et al. 2015b, Bodin et al. 2016a). Here, we build on this approach by theorizing network configurations that predispose actors in a SES with the capacity to adapt to changing conditions and to begin a transformation. The network configurations we propose can be viewed as the building blocks of a SES "governance network," loosely defined as formal and informal interactions among different types of actors that make decisions affecting environmental governance (Robins et al. 2011, Cohen et al. 2012, Alexander et al. 2016).

Importantly, the network configurations we propose act as "preconditions" for adaptation and transformation-in other words, they can be understood as key features of adaptive capacity (Nelson et al. 2007). This distinction is important because transformations consist of several phases (Olsson et al. 2004, Park et al. 2012), and we would expect networks to shift as transformations unfold (Folke et al. 2010). For example, building trust and bonding social capital are thought to be critically important for "navigating" transformations (Gelcich et al. 2010), which is typically identified as the second of three phases (but see Park et al. 2012 and Moore et al. 2014, who identify four phases). In contrast, other network capacities, such as ties that link actors across multiple scales, are thought to be important for facilitating the initial phase of transformation. It is the latter (i.e., the preconditions) that we focus on here. We also acknowledge that, despite the presence of a favorable social structural foundation, whether individuals, groups, or organizations actually implement effective adaptations and transformative change depends on social, political, and economic factors, such as the norms, intent, and power of the actors involved (Morrison 2017). Thus, we do not claim that network capacities alone fully explain the success or failure of environmental governance. Rather, we argue that poor structure can predispose failure, but good structure does not guarantee success. Thus, we posit that the network configurations we identify here form the necessary-but not sufficientconditions for adaptation and transformation to occur.

\section{Network capacities for effective adaptation and transformation}

The seven network configurations representing different network capacities that we discuss here are presented in Fig. 3. Critically, we argue that all configurations play a key role in facilitating effective responses to change. However, in line with our argument that adaptation and transformation lie along a gradient associated with different layers of rules (Fig. 1), we hypothesize that some capacities are "more" likely to be critical when adaptive action is required, and others when transformative action is required. This is reflected by their placement along a continuum that mirrors the adaptation-transformation gradient (Fig. 3). Thus, we begin our discussion on the lefthand side of the gradient, focusing primarily on adaptation, before moving sequentially to transformation on the righthand side (Fig. 3).

Adaptation is characterized by groups of actors and institutions that have accumulated knowledge on how to relate and respond to environmental feedback, allowing disturbances to enter at smaller scales instead of accumulating to larger scales (Folke et 
Fig. 3. A continuum of network configurations (i.e., network capacities) that set the stage for effective adaptation and transformation in social-ecological systems characterized by common-pool resources. In contrast to adaptation, which is a continual process, transformations involve multiple phases. The network configurations presented here are hypothesized to play a key role in the initial phase of transformations, yet may change throughout subsequent phases.
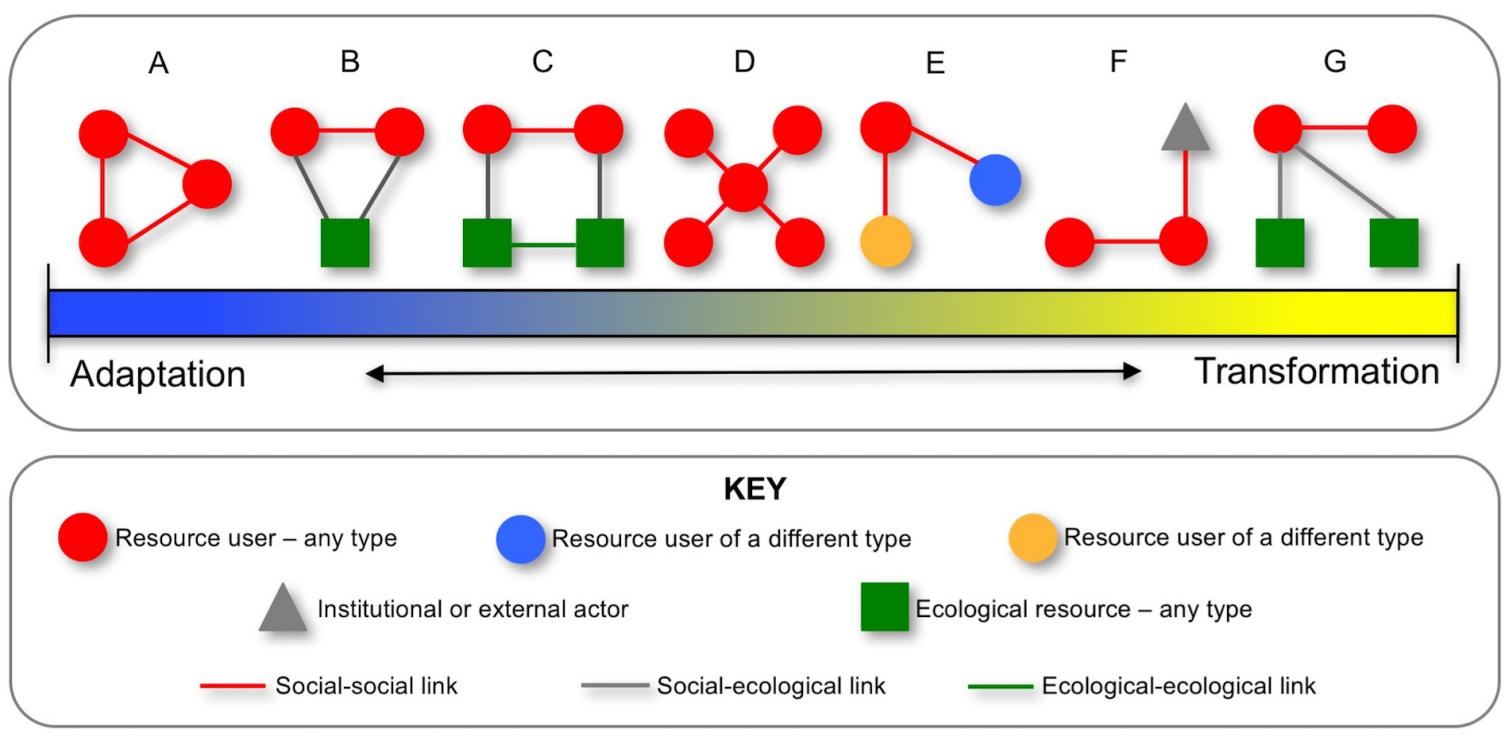

al. 2005). In a common-pool resource setting, this implies that actors are able to continuously align resource use and extraction in accordance with the accumulation of new knowledge and in response to changes in the social and ecological environment (e.g., Plummer and Armitage 2007). Thus, day-to-day adaptation (e.g., intensity of harvesting) involves changes in the operational layer (Fig. 1). Furthermore, adequate responses to social-ecological changes may sometimes require that operational rules be adjusted. For example, changes may be needed regarding when, where, and by whom operational rules should be altered, e.g., licensing (Fig. 1; e.g., Thompson et al. 2003). Central to adaptation is thus the ability to make incremental updates in the operational and possibly also the collective choice layers, both of which can be enabled by governance networks that permit close and repeated coupling of actors and the ecological resources they use and manage.

Adaptations requiring changes in the way operational rules are defined and adjusted (collective choice level) typically call for collective abilities. For example, when confronted with changing conditions not experienced previously, actors will likely need to deliberate and possibly reevaluate how they devise their operational rules. Or it can involve changes that call for adjustments in the rule-making process that might require some redistribution of actors' responsibilities and rights. In either case, high levels of bonding social capital can play a key role in facilitating effective adaptation because they can help to build trust and facilitate shared (negotiated) agreements (Adger 2003). Network closure, which involves structures of cohesive (sub) networks where actors are connected through redundant and strong connections (configuration A, Fig. 3), has a long history of being recognized as a source of bonding social capital (Burt 2005). In fact, these structures are thought to emerge as a response to perceived risks that others may not act as "agreed" (i.e., a lack of trust; Berardo and Scholz 2010, Berardo 2014). Closed network structures akin to configuration A have also been shown to facilitate learning (Prell and Lo 2016), which is crucial for combining and reinforcing existing knowledge to make incremental updates in response to change (Olsson et al. 2006, Folke et al. 2010, Fischer and Jasny 2017).

The manner in which actors depend on, or interact with, different components of ecosystems can also present opportunities for, and constraints on, adaptive action. For example, tight feedback loops, or "coupling," across the social and the ecological divide can enable actors to respond and adapt to changes more rapidly and adequately (Cumming et al. 2006, Bodin et al. 2014). Coupling can be seen as a form of social-ecological "bonding capital," which can be expressed in a number of ways. First, interactions between two or more actors that share a stake or interest in a resource are critical, i.e., configuration B, Fig. 3-or rather the lack of such interactions can be detrimental (Bodin and Tengö 2012). The presence of configuration B in the system can also ensure that actors are able to adjust their actions - guided by operational layer rules - in response to changing internal processes and demands, e.g., resource management decisions made by other actors. Ultimately, this can prevent smaller changes in the system from scaling up and having undesirable impacts on system-level outcomes (e.g., overexploitation of ecological resources; Gunderson and Holling 2002).

A focus on tight coupling in the SES also helps account for the fact that ecological systems are strongly interconnected. Parcels of vegetation are integrated in forests or farmland, whereas species of fish are connected through trophic interactions. Changes in ecosystems are thus rarely confined to just one species or location (Levin 1998). The resulting effect is that the impacts 
of management actions can spread beyond the domain of a single actor, e.g., forest fragmentation or depletion of functional species of fish in river systems. Thus, an inability to detect these spillover effects at the operational layer can result in inadequate, or even a complete lack of, adaptation (Armitage et al. 2009). For effective adaptation to occur, governance networks should account for key ecological interdependencies that are expected and relevant to the SES being managed (Christensen et al. 1996). This can be predisposed when actors directly linked to interconnected ecological resources are also connected amongst themselves, i.e., configuration $\mathrm{C}$ in Fig. 3. In this way, collaborating actors can work to coordinate management actions to minimize spillover effects at the operational layer, thus tightening feedback loops between actions and outcomes and enabling the internalization of system-level costs (and benefits) of governance (Guerrero et al. 2015a, Bodin et al. 2016a).

Once agreements are made that guide operational rules and management actions, day-to-day adaptation in response to incremental change involves the collective ability to adjust resource use across a set of resource users in a timely fashion. This typically calls for effective coordination, where a few centralized actors organize the flow of information and delegate tasks in an efficient manner (Provan and Kenis 2008, McAllister et al. 2015, Bodin et al. 2016b, McAllister et al. 2017). This type of coordination is emphasized by configuration D in Fig. 3, which represents a form of network centralization. Centralized networks are typically characterized by low transaction costs for coordinating agreed-upon actions (Carlsson and Sandström 2008). Importantly, effective coordination and low transaction costs can be enhanced if the actors involved have strong preexisting social norms and trust (facilitated by configuration A), or alternatively, are effectively governed by legislation or organizational guidelines (McAllister et al. 2017).

Akin to adaptation, embedded coordination capacity, i.e., configuration D, Fig. 3, can be critical for transformation (Olsson et al. 2006). There is perhaps one point of difference. For adaptation, we argue that coordination will relate to running somewhat regular operational tasks. However, for transformation, coordination capacity is required to allow rapid response to new shocks (Bodin et al. 2006; Alexander et al. 2017), which involves more complex tasks. Good coordination in the face of shocks can help a SES avoid the need for transformation, which can be costly. Alternatively, if some threshold is reached and an effective response cannot be executed within the realms of adaptation, then coordination can facilitate transformational change (Berardo 2014). Hence, coordinative configurations are signature to a governance network's preparedness for either transformation or adaptation, and how effective its coordination capacity is may in fact determine if its role in transformation is ever called upon.

Transformation furthermore often involves changing or crafting new constitutional rules and institutional arrangements in order to effectively respond to the substantial and typically far-reaching ecological or social change being dealt with (Moore et al. 2014). This in turn often requires bringing people together behind a common goal and coordinating heterogeneous groups of actors and actions across multiple scales (Westley et al. 2013). The existence of multiple different stakeholder groups, i.e., subgroups, is common in SESs (e.g., fishers and dive tourism operators or actors from different socioeconomic or cultural backgrounds). Importantly, such diversity among actors in SESs can pose a barrier to knowledge sharing, inhibit conflict resolution, and make process-based tasks inefficient (Carlsson and Sandström 2008, Barnes-Mauthe et al. 2013, Barnes et al. 2016). Yet successfully initiating SES transformations will almost always require diverse groups of people to overcome such barriers and work together in the social decision process to imagine new futures and take advantage of new opportunities; undertakings that often involve a need for crafting new constitutional rules (Walker et al. 2004, Wilson et al. 2013). Existing ties that link diverse groups of actors together, such as those represented by configuration E in Fig. 3 can help facilitate this by helping to build coalitions of support and bringing people together behind a common goal (Bodin and Crona 2009, Moore et al. 2014). Diversity among actors can also be leveraged to increase the pool of knowledge and thinking, which can better equip people to deal with unknown social or ecological changes (Granovetter 1973, Reagans and Zuckerman 2001, Fischer and Jasny 2017). Connections between actors with different attributes, such as knowledge types, resources, etc. (configuration E, Fig. 3), are thus an essential form of diversity that can help accomplish informed deliberation or innovation.

Making adjustments in the constitutional layer to facilitate a transformation typically necessitates the involvement of institutional or external actors and centrally located brokers that can bolster cross-scale cooperation (King 2000, Carlsson and Sandström 2008). Thus, the possession of ties to such actors (e.g. organizations, agencies) that sit outside of the core resource-use system can be critical. These types of relationships can increase the diversity of responses and help mobilize broad support while promoting legitimacy (Adger 2003, Folke et al. 2005, Walker et al. 2006). This argument parallels theory that espouses the need for nested institutions that cut across scales (Brondizio et al. 2009, Ostrom 2012). Not every actor needs such links, but we argue that it is important for those with such links (Ernstson et al. 2010) to be well connected (i.e., popular) among their own peers, i.e., configuration F, Fig. 3, allowing them to act as effective brokers (Alexander et al. 2015). Thus, the central actor in configuration $F$ is connected both across different hierarchies, or scales, but also to his or her own peers in the SES (the depiction of only one withinSES tie in Fig 3. is for simplicity of representation - it incorporates the idea that there could be many such ties).

Diversity can also present as patchiness of resource ownership, where resourceful actors linked to multiple resources offer distinctive thinking and knowledge. Having actors linked to multiple, distinct environmental resources, i.e., configuration $\mathrm{G}$, Fig. 3, can also facilitate experimentation while reducing risk, which is critical in the initial phase of transformation (Folke et al. 2005, 2010). If these actors are also well connected socially, represented by configuration $G$, it provides an avenue for knowledge sharing concerning the results. Furthermore, resourceful (and thus powerful or influential; see, e.g., Morrison et al. 2017) actors may be more predisposed to the status quo than others and thus potentially pose a barrier to change (Crona and Bodin 2010). Ensuring resourceful actors linked to multiple environmental resources are also well connected socially thus provides a greater chance that they become engaged in discussions about potential alternative futures, rather than being mentally locked in to current trajectories (although we also acknowledge 
that resourceful actors might use a socially well-connected position to advocate the preservation of the status quo; see Crona and Bodin 2010). Indeed, social ties to other actors can translate to social pressure, providing an incentive for resourceful actors to change (Nyborg et al. 2016).

Configurations E, F, and G, Fig. 3, all represent a form of network brokerage (Burt 2005). This predisposes diversity and allows some actors to reach out beyond their immediate structural environment and span across social and ecological boundaries. Brokers can spread ideas, new knowledge, and resources throughout the social system more efficiently than more isolated individuals (Olsson et al. 2006, Alexander et al. 2015). However, it is important to note that not all actors can be brokers (otherwise there is nothing left to broker). Further still, brokerage can be expensive - the time and energy requirements suggest it is inefficient for everyone to play such roles (Barnes et al. 2017), especially if the system is responding to crisis. The key point, however, is that governance networks predisposed to be able to transform when or if required need some level of brokerage capacity in at least some key parts of their network (Alexander et al. 2017). Our arguments for the relevance of these brokerage configurations thus imply various forms of political action to motivate and establish transformation across the SES, with the underlying assumption that successful transformation tends to require more overt responses than adaptation because of the more fundamental and far-reaching changes the governance system is exposed to.

However, as reflected by the adaptation-transformation gradient in Figs. 1 and 3, it is important to note that when adaptive or transformative action is required, the network capacity needs of a particular system may shift along the continuum according to its context and scale. For example, when adaptation is required, the needs of small-scale common-pool resource systems (e.g., coastal small-scale fisheries) likely fall primarily on the lefthand side of the continuum. However, a large-scale common-pool resource system involving many diverse actors situated at multiple hierarchical levels spread across broad geographic scales is likely to require network capacities from both the left and to some extent the righthand side of the continuum to execute similar adaptive actions. In such larger and likely more complicated systems, social ties linking adjacent hierarchical levels (i.e., configuration F, Fig. 3) and different user groups and communities (i.e., configuration E, Fig. 3) are likely needed to facilitate adaptation and not only transformation (e.g., subordinates might need support from designated managers to adjust rules in the operational layer; whereas different communities of resource users reliant upon a resource that spans multiple locations would benefit from being in contact with one another). Furthermore, for such larger governance systems to embark on more transformational changes, case-study research suggests brokers (often referred to as institutional entrepreneurs) who are brokering across "multiple" hierarchical layers and "several different" communities are crucial to build the needed support and momentum for such changes to materialize (Rosen and Olsson 2013). This suggests that not only are the relative frequencies of the network capacities on the right more crucial for these systems to transform, the extent to how far brokering reaches horizontally and vertically is likely needed to exceed what would be sufficient in smaller governance systems. Similar arguments are applicable in terms of the importance of embedding resourceful actors in larger governance systems.

\section{Agency and network dynamics}

Although we focus on the structural preconditions for facilitating adaptation or initiating transformations, we acknowledge that structure is not everything. Even if a governance network is well placed to mobilize efforts to effectively respond to changing biophysical or social conditions, it does not mean that it will automatically deliver positive outcomes (Robins et al. 2011). How a system ultimately behaves depends on the effectiveness of governance instruments, the agency of actors, and actors' attitudes, beliefs, and intentions (Newman and Dale 2004, ElderVass 2010). However, structure is critical because a bad structure, e.g., one with different groups of actors organized into factions with no link between them, can prevent efforts to respond effectively, e.g., in times of crisis. In terms of applying our framework empirically, it would therefore be desirable to supplement network data with other types of data to study the shared motivations, goals, and norms of actors within a SES. Leveraging such diverse data would also help to strengthen the links between the structural configurations identified here and the social processes that, over time, facilitate adaptive and transformative action.

Equally important is the issue of temporal network dynamicsparticularly in relation to transformation. In line with existing research on transformation, we argue that the configurations presented here are the building blocks that predispose a governance network to deal with future, yet unknown, needs to transform. Yet once transformation begins to occur and shift through different phases, the network is likely to change, and other configurations reflecting different capacities may become more important. For example, we would expect to see a greater number of configuration A, Fig. 3, which are associated with reciprocity and bonding social capital, in the trust-building stage often linked with the second or third phase of transformation (Moore et al. 2014). Yet too much of configuration A could actually pose a barrier to initiating a transformation due to the potential for constraining social norms or mental lock-ins that can reduce the diversity of ideas and pose barriers to experimentation (Newman and Dale 2004, Dowd et al. 2014). Therefore, it is important to reinforce that our hypothesized configurations relate to a network's latent transformative capacity. In contrast, we assume a governance network predisposed to effectively deal with challenges within the same system (i.e., adaptation) remains fundamentally the same throughout adaptation processes, although some actors may naturally change practices and their positions in the network. This reflects the view that adaptation is a continual process without a clear start and end point-a research area ripe for future, longitudinal analyses.

\section{EMPIRICAL APPLICATIONS OF THE FRAMEWORK}

We have put forth a theoretical framework with testable hypotheses about SES structures that predispose a system's ability to respond to changes either through adaptation or transformation. The challenge is now to test these hypotheses empirically. This will require detailed social-ecological network data that are collected across several different but comparable cases. This should ideally be complemented by the gathering of relevant longitudinal data that can be used to assess the extent to 
which a case has adapted or transformed. Such assessments could, for example, be based on an examination of whether rule changes over time are best described as operational or constitutional (Fig. 1). Examining how these changes relate to the underlying socialecological network structure and the continuum of capacities identified here (Fig. 3) offers real potential to provide strong tests of our hypotheses and push the limits of our current understanding.

Such a research endeavor has a strong foundation to build on. To demonstrate this, we reviewed existing studies that use a building block approach to examine the configurations put forth in our framework in related environmental governance contexts (Fig. 4). To demonstrate the flexibility associated with applying our framework empirically, we also reviewed key papers that adopted other structural social network approaches to explore the social processes captured by the configurations (Fig. 4). Demonstrated in Fig. 4, many of the configurations put forth here have been previously examined as components of past empirical research focused on environmental problem solving. Yet no studies have comprehensively examined them together or specifically examined network configurations [as defined here, following Moreno and Jennings (1938)] in relation to adaptation and transformation. Thus, our review highlighted (1) the feasibility of our approach, with multilevel network reasoning about SESs now well introduced in the literature, (2) the types of methodological approaches employed, and (3) by nature of the disparity in findings associated with specific configurations, the expectation that any future studies on adaptation and transformation can expect to find important distinctions across a range of contexts.

Described in Fig. 4, there are several distinct methodological approaches currently in use that can be adopted or expanded to investigate our framework. Exponential random graph models (ERGMs) provide a promising way forward because they model observed network structure as a function of specific network configurations and nodal attributes and are able to account for potentially overlapping configurations (Lusher et al. 2012). They can also be extended to account for multilevel networks (Wang et al. 2016), e.g., social-ecological networks. However, when applying this approach, it is important that one keep in mind the theoretical foundation of how the configurations presented in Fig. 3 explicitly relate to the social processes that facilitate adaptation or transformation, as the absence of links in certain configurations will need to be explicitly modeled in order to capture meaningful effects (e.g., the absence of links between disconnected nodes in configurations $\mathrm{E}-\mathrm{G}$ ). Thus, in a ERGM context where the lack of a tie in any given configuration implies that it may or may not be present, one should ideally control for the explicit lack of ties by modeling configurations both including and not including those ties, and then comparing the assessed coefficients for these specific configurations.

A descriptive frequency analysis, where the mean of each specific configuration of interest is compared to the mean from a large number of randomly generated graphs with the same number of nodes and links, offers a simpler yet less comprehensive alternative (see Bodin and Tengö 2012, Bodin et al. 2016a). Such analysis, however, directly accounts for the absence of a tie in any given configuration. There are also other methods to explore the processes captured by the configurations we propose that do not rely on testing the microlevel configuration specifically, e.g., standard social network analysis tools and qualitative approaches (Fig. 4). Many of these tools have often been merged together in a mixed method approach (e.g., Barnes et al. 2016; Alexander et al. 2017; Morgans et al. 2017), which may be more appropriate for capturing certain processes, depending on the context. Furthermore, it is important to acknowledge that any given social process does not necessarily correspond to one and only one microlevel configuration. Similarly, any given configuration is not necessarily the result of one and only one process. This further emphasizes the utility of combining different methods in multiple cases in order to better triangulate relationships between socialecological structures and processes.

A key critique of prior work uncovered in our review is a lack of empirical data on network performance or system-level outcomes coupled with information on potentially competing or complementary explanations that may help explain observed outcomes. Such data are crucial for furthering research in this area. Thus, despite the analytical approach employed, future empirical network data collection efforts should be coupled with comparable data on contextual (and potentially confounding) factors in addition to data on performance or outcomes that captures successes and failures of adaptive and transformative actions.

\section{CONCLUSION}

Here we have argued that a more formalized approach is needed to advance research on the role of social networks in adaptation and transformation. To this end, we have provided a framework that puts forth several hypotheses, expressed from an interdisciplinary social-ecological network perspective, regarding the capacities that lay the foundation for adaptation and transformation to occur. Further development of our hypotheses, particularly as more data become available, can provide a better understanding of the types of governance networks that facilitate adaptation and transformative change in different contexts and when faced with varying magnitudes of environmental problems - ultimately informing the design of more effective institutional arrangements.

The proposed relationships between adaptation, transformation, and various network configurations in SESs (Fig. 3) suggest that tradeoffs may exist in regard to potentially "optimizing" a network for both adaptation and transformation (Bodin and Crona 2009, Moore et al. 2014). Maximizing the configurations conducive to adaptation could mean that the sheer magnitude of configurations conducive to transformation decreases. This poses a challenge because actors should ideally make an informed choice about the abilities they want to prioritize. However, as transformations by nature tend to involve a great deal of uncertainty and surprise, making an informed choice concerning if and when to strive for transformative capacity, which may inevitably be at the expense of building the collective ability to adapt, will be difficult. We therefore propose that a SES needs to strive for both adaptation and transformation while acknowledging the potential for tradeoffs. The challenge may be to find a good balance - the "sweet spot" - where you get as much as possible of both. In social-ecological network terms, this could be conceptualized as a structure where all configurations presented in Fig. 3 are well represented, although most (or all of 
Fig. 4. Empirical investigations of network configurations in related environmental governance contexts $(E R G M=$ exponential random graph model; ML-ERGM = multilevel exponential random graph model; FA = descriptive frequency approach; $\mathrm{M}=$ mixed methods).

\begin{tabular}{|c|c|c|c|c|}
\hline $\begin{array}{l}\text { Network } \\
\text { configuration }\end{array}$ & $\begin{array}{l}\text { Existing } \\
\text { empirical } \\
\text { evidence }^{\dagger}\end{array}$ & $\begin{array}{l}\text { Process of } \\
\text { interest }\end{array}$ & $\begin{array}{l}\text { Measurement } \\
\text { approach }\end{array}$ & Results \\
\hline \multirow{3}{*}{ A } & $\begin{array}{l}\text { Berardo } \\
(2014)\end{array}$ & $\begin{array}{l}\text { Bridging } \\
\text { social capital }\end{array}$ & ERGM & $\begin{array}{l}\text { Overrepresented in a water management policy network that was more } \\
\text { favorably structured for bridging; no data on outcomes. } \neq\end{array}$ \\
\hline & $\begin{array}{l}\text { Guerrero et al. } \\
(2015 b)\end{array}$ & Coordination & ML-ERGM & $\begin{array}{l}\text { Overrepresented in a governance network of a large-scale conservation } \\
\text { initiative; no data on outcomes. }{ }^{\ddagger}\end{array}$ \\
\hline & $\begin{array}{l}\text { Lubell et al. } \\
(2016)\end{array}$ & Coordination & $\mathrm{M}^{\S}$ & $\begin{array}{l}\text { A highly centralized structure with a core set of actors in a policy network } \\
\text { facilitated the coordination necessary to eradicate an invasive species. }\end{array}$ \\
\hline \multirow{3}{*}{ B } & $\begin{array}{l}\text { Berardo } \\
(2014)\end{array}$ & $\begin{array}{l}\text { Bonding } \\
\text { social capital }\end{array}$ & ERGM & $\begin{array}{l}\text { Underrepresented in a water management policy network whose } \\
\text { structure favored coordination through bridging; no data on outcomes. } \neq\end{array}$ \\
\hline & $\begin{array}{l}\text { Guerrero et al. } \\
(2015 \mathrm{~b})\end{array}$ & $\begin{array}{l}\text { Closure/ } \\
\text { bonding }\end{array}$ & ML-ERGM & $\begin{array}{l}\text { Neither over or underrepresented in a governance network of a large- } \\
\text { scale conservation initiative that was more favorably structured for } \\
\text { coordinating conservation actions; no data on outcomes. }{ }^{\ddagger}\end{array}$ \\
\hline & $\begin{array}{l}\text { Bodin et al. } \\
(2016 b)\end{array}$ & Closure/trust & ERGM & $\begin{array}{l}\text { Overrepresented in a network of actors undertaking coastal ecosystem- } \\
\text { based management planning, where the ability to address contested } \\
\text { issues was observed. }\end{array}$ \\
\hline \multirow{3}{*}{ C } & $\begin{array}{l}\text { Bodin et al. } \\
(2014 ; 2016 a)\end{array}$ & Cooperation & FA & $\begin{array}{l}\text { Overrepresented in a case where cooperation through comanagement of } \\
\text { forest patches was implied; underrepresented in a small-scale fishery } \\
\text { where noncooperation was implied. }\end{array}$ \\
\hline & $\begin{array}{l}\text { Guerrero et al. } \\
\text { (2015a) }\end{array}$ & Collaboration & ML-ERGM & $\begin{array}{l}\text { Overrepresented in a governance network of a large-scale conservation } \\
\text { initiative where collaborative ties were perceived by local actors to aid } \\
\text { with the performance of on-ground activities. }\end{array}$ \\
\hline & $\begin{array}{l}\text { Kininmonth et } \\
\text { al. (2015) }\end{array}$ & Collaboration & FA & $\begin{array}{l}\text { Overrepresented in a wetland governance network; no data on } \\
\text { outcomes. } \neq\end{array}$ \\
\hline \multirow{3}{*}{$\mathrm{D}$} & $\begin{array}{l}\text { Guerrero et al. } \\
(2015 a)\end{array}$ & $\begin{array}{l}\text { Scale match, } \\
\text { detecting } \\
\text { feedbacks }\end{array}$ & $\begin{array}{l}\text { Multi-level } \\
\text { ERGM }\end{array}$ & $\begin{array}{l}\text { Underrepresented in a governance network of a large-scale conservation } \\
\text { initiative where insufficient communication to manage undesirable } \\
\text { feedback loops was reported by local actors. }\end{array}$ \\
\hline & $\begin{array}{l}\text { Kininmonth et } \\
\text { al. (2015) }\end{array}$ & $\begin{array}{l}\text { Coordinated } \\
\text { management }\end{array}$ & FA & $\begin{array}{l}\text { Overrepresented in a wetland governance network; no data on } \\
\text { outcomes. }{ }^{\ddagger}\end{array}$ \\
\hline & $\begin{array}{l}\text { Bodin et al. } \\
\text { (2016a) }\end{array}$ & $\begin{array}{l}\text { Social- } \\
\text { ecological } \\
\text { scale match }\end{array}$ & $\begin{array}{l}\text { ML-ERGM; } \\
\text { FA }\end{array}$ & $\begin{array}{l}\text { Underrepresented in a common-pool resource case where management } \\
\text { was largely effective, but a lack of coordination regarding linked forest } \\
\text { patches was hypothesized to have resulted in disputes. }\end{array}$ \\
\hline \multirow[t]{4}{*}{$E$} & $\begin{array}{l}\text { Bodin \& } \\
\text { Crona (2008) }\end{array}$ & $\begin{array}{l}\text { Leadership } \\
\text { and influence }\end{array}$ & $\mathrm{M}^{\S}$ & $\begin{array}{l}\text { Key individuals with ties to higher levels who were also well connected } \\
\text { among their own peers in a small-scale fishery were present, but in this } \\
\text { case may have posed a barrier to collective action as they did not } \\
\text { perceive the resource problem as severe. This illustrates our argument } \\
\text { that structure should be seen as precondition, and that agency, } \\
\text { intentions, and norms can ultimately determine outcomes. }\end{array}$ \\
\hline & $\begin{array}{l}\text { Alexander et } \\
\text { al. (2015) }\end{array}$ & $\begin{array}{l}\text { Leadership } \\
\text { and influence }\end{array}$ & $\mathrm{M}^{\S}$ & $\begin{array}{l}\text { Key individuals with ties to higher levels who were also well connected } \\
\text { among their own were present, and may have contributed to collective } \\
\text { action and a transition to a new fishery comanagement arrangement. }\end{array}$ \\
\hline & $\begin{array}{l}\text { Guerrero et al. } \\
(2015 b)\end{array}$ & $\begin{array}{l}\text { Brokerage } \\
\text { across scales }\end{array}$ & ERGM & $\begin{array}{l}\text { Overrepresented in a governance network of a large-scale conservation } \\
\text { initiative; no data on outcomes. } \neq\end{array}$ \\
\hline & $\begin{array}{l}\text { McAllister et } \\
\text { al. (2014) }\end{array}$ & $\begin{array}{l}\text { Brokerage } \\
\text { across scales }\end{array}$ & ERGM & $\begin{array}{l}\text { Underrepresented in a climate adaptation policy network predisposed for } \\
\text { decision making within scales; no data on outcomes. }{ }^{\ddagger}\end{array}$ \\
\hline \multirow[t]{2}{*}{$\mathrm{F}$} & $\begin{array}{l}\text { Sandstrom \& } \\
\text { Rova }(2010)\end{array}$ & $\begin{array}{l}\text { Social } \\
\text { brokerage }\end{array}$ & $\mathrm{M}^{\S}$ & $\begin{array}{l}\text { Links between heterogeneous actors and organizations were present } \\
\text { and may have facilitated greater commitment to the continuous rule- } \\
\text { making process associated with fishery management. }\end{array}$ \\
\hline & $\begin{array}{l}\text { Barnes et al. } \\
(2016)\end{array}$ & $\begin{array}{l}\text { Social } \\
\text { brokerage }\end{array}$ & $\mathrm{M}^{\S}$ & $\begin{array}{l}\text { Actors who linked diverse social groups in a large-scale commercial } \\
\text { fishery were present and able to leverage heterogeneous information. }\end{array}$ \\
\hline G & - & - & - & - \\
\hline
\end{tabular}

${ }^{\dagger}$ This list of studies is representative rather than exhaustive.

₹In these cases the social processes that led to network formation were explored, and the theoretical implications regarding what this means for network function discussed.

$\S$ These examples employ a combination of social network methods to examine the structural implications captured by the configurations, but focus on whole networks rather than the microconfigurations specifically. 
them) might not be as well represented as they could be if the network was optimized for any given configuration alone.

Mathematically, optimizing a network for a range of configurations is likely an impossible computational task due to the extremely high number of possible network structures even for relatively small networks. However, we argue that such an optimization exercise is not needed, and instead it might be useful to see this as a form of general resilience (Walker 2010). General resilience differs from specialized resilience in that the latter is about defining resilience in light of a specific threat, whereas the former is about defining an ability to deal with threats in a more general sense. A network conducive to both adaptation and transformation would then be analogous to general resilience, and the key governance challenges would be to navigate the evolution of the governance network in ways that support the establishment of all configurations conducive to transformation and adaptation instead of trying to optimize toward a given and prespecified structure.

The purpose of this paper is to chart a roadmap for future research. Having hypothesized a continuum of network configurations that help to distinguish between the predisposition for adaptation and transformation, empirical case studies are now needed to develop and test such ideas further. Although existing empirical investigations in related contexts include some of our hypothesized configurations (Fig. 4), some were missed and the remainder have not been examined in direct relation to adaptation or transformation. Because our hypothesized configurations are based on fairly complex interactions within SESs, it is likely that testing them will require new and purposely designed studies. The benefits of this endeavor will be twofold. One is an improved ability to identify the specifics of resilience within certain SESs. For example, such inquiries can help to uncover key socialecological feedbacks, which can improve institutional design and lead to more effective governance that is better equipped to steer systems away from undesirable states that may be difficult or impossible to reverse (i.e., social-ecological traps) (Cinner 2011). The second area of benefit relates more broadly to expanding the utility of network sciences (Lubell et al. 2012, 2017). Network methodologies have already yielded powerful insights into the role of structure on social behavior. The framework we propose here explicitly seeks to bolster the links between network methods and SES theory. Good theory can extend the utility of any empirical research beyond the bounds of the empirical results alone. Theory does this by offering a process-based understanding of how the results came to be-not just what they are-and it is this understanding that broadens the scope of where and how any learning can be applied. Thus, our approach stands not only to use emerging network sciences to provide a strong empirical basis to SES thinking, but correspondingly to give network sciences greater impact by enabling stronger links to the literature focused on how, why, and when social and ecological interactions matter.

\section{Responses to this article can be read online at:} http://www.ecologyandsociety.org/issues/responses. php/9769

\section{Acknowledgments:}

M.B. was supported by NSF Social, Behavioral, and Economic Sciences Postdoctoral Research Fellowship Grant \#1513354 and the Australian Research Council Centre of Excellence for Coral Reef Studies. S. A. acknowledges support from the Social Sciences and Humanities Research Council of Canada and the National Socio-Environmental Synthesis Center through NSF Grant \#DBI-1052875. A.G. and Ö.B. acknowledge support from the Australian Research Council Centre of Excellence for Environmental Decisions (CE11001000104). Ö.B. also acknowledges support from MISTRA.

\section{LITERATURE CITED}

Adger, W. N. 2003. Social capital, collective action, and adaptation to climate change. Economic Geography 79:387-404. http://dx.doi.org/10.1111/j.1944-8287.2003.tb00220.x

Adger, W. N., N. W. Arnell, and E. L. Tompkins. 2005. Successful adaptation to climate change across scales. Global Environmental Change 15:77-86. http://dx.doi.org/10.1016/j.gloenvcha.2004.12.005

Alexander, S. M., M. Andrachuk, and D. Armitage. 2016. Navigating governance networks for community-based conservation. Frontiers in Ecology and the Environment 14:155164.

Alexander, S. M., D. Armitage, P. Carrington, and Ö. Bodin. 2017. Examining horizontal and vertical social ties to achieve socialecological fit in an emerging marine reserve network. Aquatic Conservation: Marine and Freshwater Ecosystems [online early]. http://dx.doi.org/10.1002/aqc. 2775

Alexander, S. M., D. Armitage, and A. Charles. 2015. Social networks and transitions to co-management in Jamaican marine reserves and small-scale fisheries. Global Environmental Change 35:213-225. http://dx.doi.org/10.1016/j.gloenvcha.2015.09.001

Armitage, D., R. Plummer, F. Berkes, R. Arthur, A. T. Charles, I. Davidson-Hunt, A. Diduck, D. N, J. D, M. Marschke, P. McConney, E. Pinkerton, and E. Wollenberg. 2009. Adaptive comanagement for social-ecological complexity. Frontiers in Ecology and the Environment 7:95-102. http://dx.doi. org/10.1890/070089

Barnes, M. L., S. Arita, K. Kalberg, and P. Leung. 2017. When does it pay to cooperate? Strategic information exchange in the harvest of common-pool fishery resources. Ecological Economics 131:1-11. http://dx.doi.org/10.1016/j.ecolecon.2016.08.005

Barnes, M., J. Lynham, K. Kalberg, and P. S. Leung. 2016. Social networks and environmental outcomes. Proceedings of the National Academy of Sciences 113:6466-6471. http://dx.doi. org/10.1073/pnas.1523245113

Barnes-Mauthe, M., S. Arita, S. D. Allen, S. A. Gray, and P. S. Leung. 2013. The influence of ethnic diversity on social network structure in a common-pool resource system: implications for collaborative management. Ecology and Society 18(1):23. http:// dx.doi.org/10.5751/ES-05295-180123 
Berardo, R. 2014. Bridging and bonding capital in two mode collaboration networks. Policy Studies Journal 42:197-225. http:// dx.doi.org/10.1111/psj.12056

Berardo, R., and J. T. Scholz. 2010. Self organizing policy networks: risk, partner selection, and cooperation in estuaries. American Journal of Political Science 54:632-649. http://dx.doi. org/10.1111/j.1540-5907.2010.00451.X

Bergsten, A., D. Galafassi, and Ö. Bodin. 2014. The problem of spatial fit in social-ecological systems: detecting mismatches between ecological connectivity and land management in an urban region. Ecology and Society 19(4):6. http://dx.doi. org/10.5751/ES-06931-190406

Berkes, F., J. Colding, and C. Folke. 2003. Navigating socialecological systems: building resilience for complexity and change. Cambridge University Press, Cambridge, UK. http://dx.doi. org/10.1017/CBO9780511541957

Berkes, F., and C. S. Seixas. 2005. Building resilience in lagoon social-ecological systems: a local-level perspective. Ecosystems 8:967-974. http://dx.doi.org/10.1007/s10021-005-0140-4

Bodin, Ö. 2017. Collaborative environmental governance: achieving collective action in social-ecological systems. Science 357(6352):eaan1114. http://dx.doi.org/10.1126/science.aan1114

Bodin, Ö., B. Crona, and H. Ernstson. 2006. Social networks in natural resource management: what is there to learn from a structural perspective. Ecology and Society 11(2):r2. http://dx.doi. org/https://doi.org/10.5751/ES-01808-1102r02

Bodin, Ö., B. Crona, M. Thyresson, A.-L. Golz, and M. Tengo. 2014. Conservation success as a function of good alignment of social and ecological structures and processes. Conservation Biology 28:1371-1379. http://dx.doi.org/10.1111/cobi.12306

Bodin, Ö., and B. I. Crona. 2009. The role of social networks in natural resource governance: what relational patterns make a difference? Global Environmental Change 19:366-374. http://dx. doi.org/https://doi.org/10.1016/j.gloenvcha.2009.05.002

Bodin, Ö., G. Robins, R. McAllister, A. Guerrero, B. Crona, M. Tengö, and M. Lubell. 2016a. Theorizing benefits and constraints in collaborative environmental governance: a transdisciplinary social-ecological network approach for empirical investigations. Ecology and Society 21(1):40. http://dx.doi.org/https://doi. org/10.5751/ES-08368-210140

Bodin, Ö., A. Sandström, and B. Crona. 2016b. Collaborative networks for effective ecosystem based management: a set of working hypotheses. Policy Studies Journal 45: 289-314. http:// dx.doi.org/https://doi.org/10.1111/psj.12146

Bodin, Ö., and M. Tengö. 2012. Disentangling intangible socialecological systems. Global Environmental Change 22:430-439. http://dx.doi.org/10.1016/j.gloenvcha.2012.01.005

Brondizio, E. S., E. Ostrom, and O. R. Young. 2009. Connectivity and the governance of multilevel social-ecological systems: the role of social capital. Annual Review of Environment and Resources 34:253-278. http://dx.doi.org/10.1146/annurev.environ.020708.100707

Burt, R. S. 2005. Brokerage and closure: an introduction to social capital. Oxford University Press, New York, New York, USA.
Carlsson, L. G., and A. C. Sandström. 2008. Network governance of the commons. International Journal of the Commons 2:33-54. http://dx.doi.org/10.18352/ijc.20

Carpenter, S. R., and W. A. Brock. 2008. Adaptive capacity and traps. Ecology and Society 13(2):40. http://dx.doi.org/10.5751/ ES-02716-130240

Chaffin, B. C., A. S. Garmestani, L. Gunderson, M. H. Benson, D. G. Angeler, C. A. Arnold, B. Cosens, R. K. Craig, J. Ruhl, and C. R. Allen. 2016. Transformative environmental governance. Annual Review of Environment and Resources 41:339-423. http:// dx.doi.org/10.1146/annurev-environ-110615-085817

Christensen, N. L., A. M. Bartuska, J. H. Brown, S. Carpenter, C. D'Antonio, R. Francis, J. F. Franklin, J. A. MacMahon, R. F. Noss, and D. J. Parsons. 1996. The report of the Ecological Society of America committee on the scientific basis for ecosystem management. Ecological Applications 6:665-691. http://dx.doi. org/10.2307/2269460

Cinner, J. E. 2011. Social-ecological traps in reef fisheries. Global Environmental Change 21:835-839. http://dx.doi.org/10.1016/j. gloenvcha.2011.04.012

Cohen, P. J., L. S. Evans, and M. Mills. 2012. Social networks supporting governance of coastal ecosystems in Solomon Islands. Conservation Letters 5:376-386. http://dx.doi.org/10.1111/ j.1755-263X.2012.00255.X

Crona, B., and Ö. Bodin. 2010. Power asymmetries in small-scale fisheries: a barrier to governance transformability? Ecology and Society 15(4):32. http://dx.doi.org/https://doi.org/10.5751/

ES-03710-150432

Cumming, G. S., D. H. M. Cumming, and C. L. Redman. 2006. Scale mismatches in social-ecological systems: causes, consequences, and solutions. Ecology and Society 11(1):14. http:// dx.doi.org/10.5751/ES-01569-110114

Dowd, A.-M., N. Marshall, A. Fleming, E. Jakku, E. Gaillard, and M. Howden. 2014. The role of networks in transforming Australian agriculture. Nature Climate Change 4:558-563. http:// dx.doi.org/10.1038/nclimate2275

Elder-Vass, D. 2010. The causal power of social structures: emergence, structure and agency. Cambridge University Press, New York, New York, USA. http://dx.doi.org/10.1017/ $\underline{\text { CBO9780511761720 }}$

Engle, N. L. 2011. Adaptive capacity and its assessment. Global Environmental Change 21:647-656. http://dx.doi.org/10.1016/j. gloenvcha.2011.01.019

Ernstson, H., S. Barthel, E. Andersson, and S. T. Borgström. 2010. Scale-crossing brokers and network governance of urban ecosystem services: the case of Stockholm. Ecology and Society 15(4):28. http://dx.doi.org/10.5751/ES-03692-150428

Fischer, A., and L. Jasny. 2017. Capacity to adapt to environmental change: evidence from a network of organizations concerned with increasing wildfire risk. Ecology and Society 22 (1):23. http://dx.doi.org/10.5751/ES-08867-220123

Folke, C., S. R. Carpenter, B. Walker, M. Scheffer, T. Chapin, and J. Rockstrom. 2010. Resilience thinking: integrating resilience, 
adaptability and transformability. Ecology and Society 15(4):20. http://dx.doi.org/10.5751/ES-03610-150420

Folke, C., J. Colding, and F. Berkes. 2003. Synthesis: building resilience and adaptive capacity in social-ecological systems. Pages 352-387 in F. Berkes, J. Colding, and C. Folke, editors. Navigating social-ecological systems: building resilience for complexity and change. Cambridge University Press, New York, New York, USA. http://dx.doi.org/10.1017/CBO9780511541957.020

Folke, C., T. Hahn, P. Olsson, and J. Norberg. 2005. Adaptive governance of social-ecological systems. Annual Review of Environment and Resources 30:441-473. http://dx.doi.org/10.1146/ annurev.energy.30.050504.144511

Gelcich, S., T. P. Hughes, P. Olsson, C. Folke, O. Defeo, M. Fernández, S. Foale, L. H. Gunderson, C. Rodríguez-Sickert, and M. Scheffer. 2010. Navigating transformations in governance of Chilean marine coastal resources. Proceedings of the National Academy of Sciences 107:16794-16799. http://dx.doi.org/10.1073/ pnas. 1012021107

Granovetter, M. S. 1973. The strength of weak ties. American Journal of Sociology 78:1360-1380. http://dx.doi.org/10.1086/225469

Guerrero, A., Ö. Bodin, R. McAllister, and K. Wilson. $2015 a$. Achieving social-ecological fit through bottom-up collaborative governance: an empirical investigation. Ecology and Society 20 (4):41. http://dx.doi.org/https://doi.org/10.5751/ES-08035-200441

Guerrero, A. M., R. R. Mcallister, and K. A. Wilson. $2015 b$. Achieving cross scale collaboration for large scale conservation initiatives. Conservation Letters 8:107-117. http://dx.doi.org/ https://doi.org/10.1111/conl.12112

Gunderson, L. H., and C. S. Holling. 2002. Panarchy: understanding transformations in human and natural systems. Island Press, Washington, D.C., USA.

Hardin, G. 1968. The tragedy of the commons. Science 162:12431248. http://dx.doi.org/10.1126/science.162.3859.1243

Henry, A. D., and B. Vollan. 2014. Networks and the challenge of sustainable development. Annual Review of Environment and Resources 39:583-610. http://dx.doi.org/10.1146/annurevenviron-101813-013246

Holland, P. W., and S. Leinhardt. 1970. A method for detecting structure in sociometric data. American Journal of Sociology 76:492-513. http://dx.doi.org/10.1086/224954

Hughes, T. P., M. L. Barnes, D. R. Bellwood, J. E. Cinner, G. S. Cumming, J. B. Jackson, J. Kleypas, I. A. van de Leemput, J. M. Lough, and T. H. Morrison. 2017. Coral reefs in the Anthropocene. Nature 546:82-90. http://dx.doi.org/10.1038/ nature22901

King, A. 2000. Managing without institutions: the role of communication networks in governing resource access and control. University of Warwick, Coventry, UK.

Kininmonth, S., A. Bergsten, and Ö. Bodin. 2015. Closing the collaborative gap: aligning social and ecological connectivity for better management of interconnected wetlands. Ambio 44:138148. http://dx.doi.org/10.1007/s13280-014-0605-9

Kiser, L. L., and E. Ostrom. 1982. The three worlds of action: a metatheoretical synthesis of institutional approaches. Pages 179-
222 in E. Ostrom, editor. Strategies of political inquiry. Sage, Beverly Hills, California, USA.

Kittinger, J. N., E. M. Finkbeiner, N. C. Ban, K. Broad, M. H. Carr, J. E. Cinner, S. Gelcich, M. L. Cornwell, J. Z. Koehn, and X. Basurto. 2013. Emerging frontiers in social-ecological systems research for sustainability of small-scale fisheries. Current Opinion in Environmental Sustainability 5:352-357. http://dx.doi. org/10.1016/j.cosust.2013.06.008

Levin, S. A. 1998. Ecosystems and the biosphere as complex adaptive systems. Ecosystems 1:431-436. http://dx.doi.org/10.1007/ $\underline{\text { s100219900037 }}$

Lubell, M., L. Jasny, and A. Hastings. 2017. Network governance for invasive species management. Conservation Letters: online early. http://dx.doi.org/10.1111/conl.12311

Lubell, M., J. Scholz, R. Berardo, and G. Robins. 2012. Testing policy theory with statistical models of networks. Policy Studies Journal 40:351-374. http://dx.doi.org/10.1111/j.1541-0072.2012.00457. $\underline{x}$

Lusher, D., J. Koskinen, and G. Robins. 2012. Exponential random graph models for socialnetworks: theory, methods, and applications. Cambridge University Press, New York, New York, USA. http:// dx.doi.org/10.1017/CBO9780511894701

McAllister, R.R., R. McCrea, and M.N. Lubell. 2014. Policy networks, stakeholder interactions and climate adaptation in the region of South East Queensland, Australia. Regional Environmental Change 14:527-539. http://dx.doi.org/10.1007/ s10113-013-0489-4

McAllister, R. R., C. J. Robinson, K. Maclean, A. M. Guerrero, K. Collins, B. M. Taylor, and P. J. De Barro. 2015. From local to central: a network analysis of who manages plant pest and disease outbreaks across scales. Ecology and Society 20(1):67. http://dx. doi.org/10.5751/ES-07469-200167

McAllister, R. R. J., C. J. Robinson, K. MacLean, S. Perry, L. Shuang, and B. Alinta. 2017. Balancing collaboration with coordination: contesting eradication in the Australian plant pest and disease biosecurity system. International Journal of the Commons 11(1):330-354. http://dx.doi.org/10.18352/ijc.701

McGinnis, M. D., and E. Ostrom. 2014. Social-ecological system framework: initial changes and continuing challenges. Ecology and Society 19(2): 30. http://dx.doi.org/10.5751/ES-06387-190230

Milo, R., S. Shen-Orr, S. Itzkovitz, N. Kashtan, D. Chklovskii, and U. Alon. 2002. Network motifs: simple building blocks of complex networks. Science 298:824-827. http://dx.doi.org/10.1126/ science.298.5594.824

Moore, M.-L., O. Tjornbo, E. Enfors, C. Knapp, J. Hodbod, J. A. Baggio, A. Norström, P. Olsson, and D. Biggs. 2014. Studying the complexity of change: toward an analytical framework for understanding deliberate social-ecological transformations. Ecology and Society 19(4):54. http://dx.doi.org/10.5751/ ES-06966-190454

Moreno, J. L., and H. H. Jennings. 1938. Statistics of social configurations. Sociometry 1(3-4): 342-374. http://dx.doi. org/10.2307/2785588 
Morgans, C. L., A. M. Guerrero, M. Ancrenaz, E. Meijaard, and K. A. Wilson. 2017. Not more, but strategic collaboration needed to conserve Borneo's orangutan. Global Ecology and Conservation 11:236-246. http://dx.doi.org/10.1016/j.gecco.2017.07.004

Morrison, T. H. 2017. Evolving polycentric governance of the Great Barrier Reef. Proceedings of the National Academy of Sciences 114(15): E3013-E3021 http://dx.doi.org/10.1073/ pnas. 1620830114

Morrison, T. H., W. N. Adger, K. Brown, M. C. Lemos, D. Huitema, and T. P. Hughes. 2017. Mitigation and adaptation in polycentric systems: sources of power in the pursuit of collective goals. Wiley Interdisciplinary Reviews: Climate Change 8(5):e479. http://dx.doi.org/10.1002/wcc.479

Nelson, D. R., W. N. Adger, and K. Brown. 2007. Adaptation to environmental change: contributions of a resilience framework. Annual Review of Environment and Resources 32:395-419. http:// dx.doi.org/10.1146/annurev.energy.32.051807.090348

Newman, L., and A. Dale. 2004. Network structure, diversity, and proactive resilience building: a response to Tompkins and Adger. Ecology and Society 10(1):r2. http://dx.doi.org/10.5751/ ES-01396-1001r02

Nyborg, K., J. M. Anderies, A. Dannenberg, T. Lindahl, C. Schill, M. Schlüter, W. N. Adger, K. J. Arrow, S. Barrett, and S. Carpenter. 2016. Social norms as solutions. Science 354:42-43. http://dx.doi. org/10.1126/science.aaf8317

Olsson, P., C. Folke, and T. Hahn. 2004. Social-ecological transformation for ecosystem management: the development of adaptive co-management of a wetland landscape in southern Sweden. Ecology and Society 9(4):2. http://dx.doi.org/10.5751/ ES-00683-090402

Olsson, P., L. H. Gunderson, S. R. Carpenter, P. Ryan, L. Lebel, C. Folke, and C. S. Holling. 2006. Shooting the rapids: navigating transitions to adaptive governance of social-ecological systems. Ecology and Society 11(1):18. http://dx.doi.org/10.5751/ ES-01595-110118

Ostrom, E. 1990. Governing the commons: the evolution of institutions for collective action. Cambridge University Press, Cambridge, UK. http://dx.doi.org/https://doi.org/10.1017/ $\underline{\text { CBO9780511807763 }}$

Ostrom, E. 2009. Understanding institutional diversity. Princeton University Press, Princeton, New Jersey, USA.

Ostrom, E. 2012. Polycentric systems: Multilevel governance involving a diversity of organizations. Pages 105-125 in E. Brousseau, T. Dedeurwaerdere, P. A. Jouvet, and M. Willinger, editors. Global environmental commons: analytical and political challenges in building governance mechanisms. Oxford University Press, Oxford, UK. http://dx.doi.org/10.1093/acprof: oso/9780199656202.003.0005

Park, S., N. Marshall, E. Jakku, A.-M. Dowd, S. Howden, E. Mendham, and A. Fleming. 2012. Informing adaptation responses to climate change through theories of transformation. Global Environmental Change 22:115-126. http://dx.doi. org/10.1016/j.gloenvcha.2011.10.003
Plummer, R., and D. Armitage. 2007. A resilience-based framework for evaluating adaptive co-management: linking ecology, economics and society in a complex world. Ecological Economics 61:62-74. http://dx.doi.org/10.1016/j.ecolecon.2006.09.025

Prager, S. D., and C. Pfeifer. 2015. Network approaches for understanding rainwater management from a social-ecological systems perspective. Ecology and Society 20(4):13. http://dx.doi. org/10.5751/ES-07950-200413

Prell, C., and Y.-J. Lo. 2016. Network formation and knowledge gains. The Journal of Mathematical Sociology 40:21-52. http:// dx.doi.org/10.1080/0022250X.2015.1112385

Provan, K. G., and P. Kenis. 2008. Modes of network governance: structure, management, and effectiveness. Journal of Public Administration Research and Theory 18:229-252. http://dx.doi. org/10.1093/jopart/mum015

Reagans, R., and E. W. Zuckerman. 2001. Networks, diversity, and productivity: the social capital of corporate R\&D teams. Organization Science 12:502-517. http://dx.doi.org/10.1287/ orsc. 12.4.502.10637

Robins, G., L. Bates, and P. Pattison. 2011. Network governance and environmental management: conflict and cooperation. Public Administration 89:1293-1313. http://dx.doi.org/10.1111/ j.1467-9299.2010.01884.X

Rosen, F., and P. Olsson. 2013. Institutional entrepreneurs, global networks, and the emergence of international institutions for ecosystem-based management: the Coral Triangle Initiative. Marine Policy 38:195-204. http://dx.doi.org/10.1016/j.marpol.2012.05.036

Sayles, J. S., and J. A. Baggio. 2017. Social-ecological network analysis of scale mismatches in estuary watershed restoration. Proceedings of the National Academy of Sciences 114(10):E1776E1785. http://dx.doi.org/10.1073/pnas.1604405114

Thompson, P. M., P. Sultana, and N. Islam. 2003. Lessons from community based management of floodplain fisheries in Bangladesh. Journal of Environmental Management 69:307-321. http://dx.doi.org/10.1016/j.jenvman.2003.09.014

Walker, B. 2010. General and specified resilience. Pages 34-35 in L. Gunderson, A. P. Kinzig, A. Quinlan, and B. Walker, editors. Assessing resilience in social-ecological systems: workbook for practitioners 2.0. Resilience Alliance [online] URL: http://www. reefresilience.org/pdf/ResilienceAssessment2.pdf

Walker, B., C. S. Holling, S. R. Carpenter, and A. Kinzig. 2004. Resilience, adaptability and transformability in social-ecological systems. Ecology and Society 9(2):5. http://dx.doi.org/10.5751/ ES-00650-090205

Walker, B. H., J. M. Anderies, A. P. Kinzig, and P. Ryan. 2006. Exploring resilience in social-ecological systems through comparative studies and theory development: Introduction to the special issue. Ecology and Society 11(1):12. http://dx.doi. org/10.5751/ES-01573-110112

Wang, P., G. Robins, and P. Matous. 2016. Multilevel network analysis using ERGM and its extension. Pages 125-143 in E. Lazega and T. A. B. Snijders, editors. Multilevel network analysis for the social sciences. Springer International Publishing, Basel, Switzerland. http://dx.doi.org/10.1007/978-3-319-24520-1_6 
Westley, F. R., O. Tjornbo, L. Schultz, P. Olsson, C. Folke, B. Crona, and Ö. Bodin. 2013. A theory of transformative agency in linked social-ecological systems. Ecology and Society 18(3):27. http://dx.doi.org/10.5751/ES-05072-180327

Wilson, S., L. J. Pearson, Y. Kashima, D. Lusher, and C. Pearson. 2013. Separating adaptive maintenance (resilience) and transformative capacity of social-ecological systems. Ecology and Society 18(1):22. http://dx.doi.org/10.5751/ES-05100-180122

Wise, R., I. Fazey, M. S. Smith, S. Park, H. Eakin, E. A. van Garderen, and B. Campbell. 2014. Reconceptualising adaptation to climate change as part of pathways of change and response. Global Environmental Change 28:325-336. http://dx.doi. org/10.1016/j.gloenvcha.2013.12.002 